\title{
Produção de leite em cabras alimentadas com diferentes níveis de proteína na dieta: consumo e digestibilidade dos nutrientes ${ }^{1}$
}

\author{
Carlos Elysio Moreira da Fonseca ${ }^{2}$, Rilene Ferreira Diniz Valadares ${ }^{3}$, Sebastião de Campos \\ Valadares Filho ${ }^{4}$, Marcelo Teixeira Rodrigues ${ }^{4}$, Marcos Inácio Marcondes ${ }^{5}$, Marlos Oliveira \\ Porto $^{6}$, Douglas dos Santos Pina ${ }^{6}$, Kamila Andreatta Kling de Moraes ${ }^{5}$
}

1 Parte da tese de Doutorado do primeiro autor apresentada à UFV, parcialmente financiada pelo CNPq/FAPEMIG.

2 PA/IZ/UFRRJ, Seropédica-RJ.

${ }^{3}$ DVT/UFV, Viçosa-MG.

${ }^{4}$ DZO/UFV, Viçosa-MG.

${ }^{5}$ Mestrando em Zootecnia- UFV.

${ }^{6}$ Doutorando em Zootecnia- UFV.

RESUMO - Avaliaram-se os consumos e as digestibilidades dos nutrientes e a produção e composição do leite de cabras alimentadas com dietas com $47 \%$ de silagem de milho e $53 \%$ de concentrado, contendo níveis crescentes de PB (11,5; 13,5; 15,5 e 17,5\%PB na MS). Foram utilizadas 12 cabras da raça Alpina em lactação, distribuídas em três quadrados latinos 4 x 4 compostos de quatro períodos de 15 dias (sete de adaptação às dietas e oito para coletas de amostras). Amostras de fezes e de leite foram analisadas e os resultados avaliados por meio de análises de variância e regressão. Os consumos de MS, MO, PB, PDR e NDT, assim com as digestibilidades da MS, MO, PB e CNF, aumentaram linearmente com os níveis de PB da dieta. A produção de leite aumentou linearmente com o incremento do nível dietético de $\mathrm{PB}$, enquanto a produção de leite corrigida para 3,5\% de gordura e as porcentagens de gordura e PB no leite não foram influenciadas pelos níveis de PB nas dietas. Concluiu-se que os níveis de $13,5 \%$ de $\mathrm{PB}$ ou $290 \mathrm{~g}$ de $\mathrm{PB} /$ dia atendem às exigências de proteína e parecem adequados para cabras com produção diária de até $2,7 \mathrm{~kg}$ de leite corrigido para $3,5 \%$ de gordura.

Palavras-chave: alimentação, caprinos, farelo de soja, lactação

\section{Production of goats fed diets with increasing levels of protein: intake, milk yield and apparent digestibility}

\begin{abstract}
Intake, apparent digestibility of nutrients, milk yield and milk composition were all evaluated in goats receiving diets with $47 \%$ of corn silage and $53 \%$ of concentrate. Dietary crude protein (CP) was increased as follows [dry matter (DM) basis]:11.5, 13.5, 15.5 and 17.5\%. Twelve lactating Alpine goats were randomly assigned to three 4 x 4 Latin squares with 15 days experimental periods: seven days for diet adaptation and eight days for samples collection. Total collection of feces was done from day 8 to day 12 of each period while milk samples on day 10. Data were evaluated by analysis of variance and regression. Intakes of DM, organic matter (OM), CP, rumen degradable protein (RDP) and total digestible nutrients (TDN) increased linearly with the increment of dietary CP. Similarly, digestibilities of DM, OM, CP and non-fiber carbohydrates (NFC) increased linearly when the CP level increased from 11.5 to 17.5 of the diet. Milk production also increased linearly with the increase of $\mathrm{CP}$ in the diet but no significant effects were observed for 3.5\% fat corrected (FCM) milk as well as for contents of milk fat and milk CP. It can be concluded that the diet with $13.5 \%$ of CP met the protein requirements of lactating goats and appeared to be adequate for animals yielding up to $2.7 \mathrm{~kg}$ of $3.5 \% \mathrm{FCM}$ per day.
\end{abstract}

Key Words: feeding, goat, lactation, soybean meal

\section{Introdução}

O consumo de nutrientes é o principal fator limitante na produção de ruminantes. Maximizar o consumo é fundamental para o desenvolvimento de rações e estratégias de alimentação que otimizem a produção (Rodrigues, 1998) e um dos recursos para estimular a ingestão de nutrientes consiste na adição de alimentos concentrados à dieta.
Entretanto, os concentrados protéicos têm sido responsáveis pelo alto custo de alimentação de cabras leiteiras, tornando interessante a maximização da utilização de compostos nitrogenados e determinação do nível ótimo de $\mathrm{PB}$ em dietas para cabras lactantes.

Segundo Morand-Fehr \& Sauvant (1980), a concentração de PB na dieta total deve variar entre 13 e 16\% da MS, dependendo da qualidade da proteína da dieta, da produção 
de leite e do estádio de lactação das cabras. Sahlu et al. (1993b), trabalhando com dietas contendo diferentes teores de proteína, concluíram que o aumento de 13 para $17 \%$ de PB na MS não melhorou o consumo alimentar nem a produção de leite em cabras leiteiras produzindo de 3,3 a 4,6 kg de leite/dia no início de lactação. Os autores citaram que a ausência de efeito da PB da dieta sobre o desempenho produtivo pode ter sido ocasionada pelo alto consumo de MS pelas cabras ( $4,7 \%$ do $\mathrm{PV})$.

Possivelmente, para menor consumo de MS observado em condições tropicais (Devendra, 1982), sejam necessários mais que $13 \%$ de $\mathrm{PB}$ na MS para atender às exigências de PB para máxima produção de leite.

Este trabalho foi conduzido com os objetivos de avaliar os consumos e as digestibilidades de MS, FDN, MO, PB, CT e CNF e determinar a produção e composição do leite de cabras alimentadas com diferentes níveis de PB na dieta.

\section{Material e Métodos}

O experimento foi realizado no Setor de Caprinocultura do Departamento de Zootecnia da Universidade Federal de Viçosa, no período de outubro de 2002 a janeiro de 2003.

Foram utilizadas 12 cabras da raça Alpina com peso médio de $50,8 \mathrm{~kg}$ e produção média diária de $2,8 \mathrm{~kg}$ de leite. Os animais foram confinados em baias individuais $\left(1,5 \mathrm{~m}^{2}\right)$ com piso ripado de madeira, comedouro e bebedouro individuais.

Inicialmente, os animais foram identificados e tratados contra ecto e endoparasitas. As cabras foram pesadas no início e ao final de cada período experimental, sendo distribuídas em três quadrados latinos $4 \times 4$, compostos de quatro períodos de 15 dias (sete de adaptação às dietas e oito para coleta de amostras. As cabras foram alimentadas com quatro dietas constituídas de silagem de milho (47\%) e concentrado (53\%), formuladas para conter 11,5; 13,5; 5,5 e 17,5\% de PB na MS total (Tabela 1 ) e fornecidas às $7 \mathrm{e} 16 \mathrm{~h}$, em quantidades suficientes para garantir $15 \%$ de sobras. A coleta de sobras foi feita do $8^{\circ}$ ao $15^{\circ}$ dia de cada período experimental, sendo conservadas a $-20^{\circ} \mathrm{C}$ para análises posteriores.

As fezes foram coletadas em telas colocadas sob o piso das baias, efetuando-se a coleta total do $8^{\circ}$ ao $12^{\circ}$ dia de cada período experimental. Retiraram-se subamostras de $10 \%$ do total, que foram reunidas para formar amostras compostas por animal por período, sendo armazenadas a $-20^{\circ} \mathrm{C}$ até a ocasião das análises laboratoriais.

Consta na Tabela 1 a composição percentual das dietas utilizadas no experimento, cujos teores de PB variaram de 11,3 a $17,7 \%$ e foram próximos aos preconizados.

As cabras foram ordenhadas manualmente duas vezes ao dia (às 6 e 15h) e o leite de cada cabra foi pesado
Tabela 1 - Teores médios de MS, MO, PB, PDR, EE, CT, FDN e CNF das dietas experimentais

Table 1 - Average contents of DM, OM, CP, RDP, EE, TC, NDF and NFC in the experimental diets

\begin{tabular}{lrrrr}
\hline $\begin{array}{l}\text { Item } \\
\text { Item }\end{array}$ & \multicolumn{4}{c}{$\begin{array}{c}\text { Nível de PB (\%) } \\
\text { CP level (\%) }\end{array}$} \\
\cline { 2 - 5 } & 11,5 & 13,5 & 15,5 & 17,5 \\
\hline $\mathrm{MS}(D M)(\%)$ & 62,1 & 61,3 & 63,4 & 64,1 \\
$\mathrm{MO}^{1}(O M)$ & 95,3 & 95,3 & 94,8 & 94,7 \\
$\mathrm{~PB}^{1}(C P)$ & 11,3 & 13,4 & 15,5 & 17,7 \\
$\mathrm{PDR}^{1}(R D P)$ & 7,4 & 8,9 & 10,3 & 11,8 \\
$\mathrm{EE}^{1}$ & 3,0 & 2,5 & 2,5 & 2,5 \\
$\mathrm{CT}^{1}$ (TC) & 81,0 & 79,4 & 76,8 & 74,6 \\
$\mathrm{FDN}^{1}$ (NDF) & 31,5 & 31,0 & 30,5 & 30,4 \\
$\mathrm{CNF}^{1}$ (NFC) & 49,5 & 48,4 & 46,3 & 44,2 \\
\hline
\end{tabular}

$1 \%$ na MS (\% of DM).

diariamente do $8^{\circ}$ ao $15^{\circ}$ dia de cada período. No $10^{\circ}$ dia de cada período, amostras do leite da $1 \underline{\mathrm{a}} \mathrm{e}$ da $2 \underline{\mathrm{a}}$ ordenhas foram coletadas e agrupadas em amostras compostas, proporcionais ao peso de cada ordenha para cada animal, para determinação do teor de PB.

A determinação de teor de gordura do leite foi realizada imediatamente após cada ordenha no 10 o dia de cada período. A produção de leite foi corrigida para 3,5\% de gordura (LCG), utilizando-se a equação de Gaines (1928): LCG 3,5\% $=(0,4255 \times \mathrm{kg}$ leite $)+[16,425 \times(\%$ gordura $/ 100) \times(\mathrm{kg}$ leite $)]$.

A eficiência alimentar foi calculada por meio da divisão da quantidade de leite produzida ( $\mathrm{kg} / \mathrm{dia}$ ) pela quantidade de alimento ingerido ( $\mathrm{kg}$ de MS /dia). Determinou-se a eficiência de utilização de $\mathrm{N}$ pela divisão da quantidade de $\mathrm{N}$ secretada no leite produzido ( $\mathrm{g} / \mathrm{dia}$ ) pela quantidade de $\mathrm{N}$ ingerido (g/dia).

As amostras de alimentos, sobras e fezes foram secas a $65^{\circ} \mathrm{C}$ em estufa de ventilação forçada, durante 72 horas, processadas em moinho tipo Willey com peneira de malha de $1 \mathrm{~mm}$ e acondicionadas individualmente em frascos de vidro. As análises dos teores de MS, CIN, compostos nitrogenados, EE e FDN dos alimentos, das sobras e das fezes foram realizadas conforme descrito por Silva \& Queiroz (2002).

A porcentagem de carboidratos totais (CT) foi obtida pela equação proposta por Sniffen et al. (1992): $\mathrm{CT}=100$ (\% $\mathrm{PB}+\% \mathrm{EE}+\%$ cinzas), utilizando-se, para o cálculo do teor de NDT, a equação proposta por Weiss (1999): NDT $=$ PBd $+2,25 \times \mathrm{EEd}+\mathrm{FDNd}+\mathrm{CNFd}$, em que PBd, EEd, FDNd e CNFd significam, respectivamente, $\mathrm{PB}, \mathrm{EE}, \mathrm{FDN}$ e CNF digestíveis.

Foram calculados os consumos de MS e EM fermentada e as exigências de PDR, proteína metabolizável (PMet) e energia (NDT), de acordo com os procedimentos propostos pelo AFRC (1993).

Os valores referentes às concentrações das frações a e b da PB e de NIDA nos alimentos foram obtidos de tabelas 
de composição de alimentos (AFRC, 1993; Valadares Filho et al., 2002), expressos em decimais do nitrogênio total e em porcentagem da $\mathrm{PB}$, respectivamente.

Utilizando-se os procedimentos descritos pelo AFRC (1993), determinaram-se as exigências de MS, proteína e energia, separadamente, para as dietas experimentais: $\mathrm{EM}_{\mathrm{m}}=$ exigência de $\mathrm{EM}$ para mantença; e $\mathrm{EM}_{\mathrm{L}}=$ exigência de EM para lactação.

O consumo de EMF foi estimado multiplicando-se a concentração de EMF (MJ/kg) nos alimentos pelas respectivas quantidades consumidas pelos animais: $\operatorname{EMF}(\mathrm{MJ} / \mathrm{kg})=0,9 \times[\mathrm{EM}]-0,035[\mathrm{EE}]$, para silagem de milho; e EMF $(\mathrm{MJ} / \mathrm{kg})=[\mathrm{EM}]-0,035[\mathrm{EE}]$, para os concentrados, em que EM = concentração de EM do alimento, em $\mathrm{MJ} / \mathrm{kg}$; e EE = concentração de EE no alimento, em g/ $\mathrm{kg}$.

O consumo de PDR (em g/dia) foi estimado multiplicando-se o consumo dos ingredientes da dieta por suas respectivas concentrações de PDR (em g/kg), utilizando-se para silagem de milho, fubá, farelo de soja e uréia, respectivamente, os valores de 62, 52, 65 e 100\% de PDR em relação ao total de PB.

Os resultados foram avaliados por meio de análises de variância e regressão, utilizando-se o Sistema de Análises Estatísticas-SAEG (UFV, 1999), aplicando-se o teste "t" de Student a $5 \%$ de probabilidade para comparação das médias dos tratamentos.

\section{Resultados e Discussão}

O consumo médio de MS (2,12 $\mathrm{kg}$ ou 4,21\% do PV) foi próximo aos indicados por Wilkinson \& Stark (1987) e pelo AFRC (1993), que recomendam, respectivamente, 2,0 e $1,96 \mathrm{~kg}$ de MS para cabras de $50 \mathrm{~kg}$ com produção de $2,5 \mathrm{~kg}$ de leite com 3,5\% de gordura. Wilkinson \& Stark (1987) citam que o consumo de MS por cabras geralmente se situa entre 3 e $5 \%$ do peso corporal.

O consumo de MS, em kg/dia ou em porcentagem do PV, apresentou comportamento linear crescente com o aumento do teor de PB das dietas, o que está de acordo com os obtidos por Badamana et al. (1990) e Sahlu et al. (1992), que observaram aumento linear do consumo de alimento com o acréscimo no teor de proteína da dieta de caprinos. Sahlu et al. (1993b) determinaram o consumo de MS em cabras leiteiras produzindo de 3,3 a 4,6 $\mathrm{kg}$ de leite por dia durante o início de lactação, alimentadas com dietas isoenergéticas contendo diferentes níveis e fontes de proteína, e observaram que o aumento de 13 para $17 \%$ de PB na MS das dietas ou a redução da degradabilidade da $\mathrm{PB}$ do farelo de soja não influenciaram o consumo. As diferenças também não foram significativas, mesmo quando consideradas apenas as cabras com alta produção ( $>4,0 \mathrm{~kg}$ de leite/dia, $\mathrm{n}=19)$. Os autores atribuíram a ausência de efeito da PB da dieta sobre o desempenho produtivo ao alto consumo de MS $(4,7 \%$ do PV). Diferenças raciais e produção de leite também podem estar relacionadas à esta divergência entre resultados.

Na Tabela 2, são apresentados os dados referentes aos consumos médios diários de $\mathrm{MS}, \mathrm{MO}, \mathrm{PB}, \mathrm{EE}, \mathrm{CT}$, FDN, CNF e NDT, os respectivos coeficientes de variação e determinação e as equações de regressão, de acordo com o teor de $\mathrm{PB}$ das dietas.

Assim como o consumo de MS, os consumos de MO e NDT foram influenciados positivamente $(\mathrm{P}<0,01)$ pelo conteúdo de $\mathrm{PB}$ na dieta, como reflexo do aumento do consumo e da digestibilidade de MO.

Apesar de as dietas apresentarem teores decrescentes de carboidratos, resultantes da substituição de fubá por farelo de soja, os consumos de CT e CNF não foram influenciados pelos tratamentos. A ingestão crescente de MS e MO compensou os teores decrescentes de carboidratos, impedindo que houvesse diferença no consumo de carboidratos.

O consumo de FDN em gramas e em porcentagem do $\mathrm{PV}(\% \mathrm{PV})$ apresentou resposta positiva $(\mathrm{P}<0,1)$ aos teores de PB, com valores entre 1,073 e 1,198 (quando expresso em $\% \mathrm{PV}$ ), próximos ao de $1,09 \%$ do $\mathrm{PV}$ observado por Carvalho et al. (2006) em cabras lactantes alimentadas com $30,2 \%$ de FDN na dieta. Estes resultados estão de acordo com os descritos por Bomfim (2003), que observou consumo de $1,12 \%$ do PV em cabras lactantes alimentadas com dietas contendo 29 a $31 \%$ de FDN.

Os dois principais mecanismos de controle do consumo voluntário são o físico e o fisiológico. Em cabras leiteiras, estes parâmetros não estão bem definidos e, considerando os resultados de Santini et al. (1992) e Carvalho (2002), bem como o nível de consumo de FDN pelas cabras deste trabalho (até $1,2 \% \mathrm{PV}$ ), sugere-se que o mecanismo de controle de consumo dos animais não foi o físico.

Com o aumento do nível de PB na dieta, o consumo de NDT também apresentou comportamento linear crescente $(\mathrm{P}<0,01)$. Para a dieta com $11,5 \%$ de $\mathrm{PB}$, o consumo de NDT atendeu às exigências propostas pelo AFRC (1993) e foi próximo ao recomendado pelo NRC (1981). Com as demais dietas, as exigências de NDT foram satisfeitas em ambos os sistemas.

O consumo de $\mathrm{PB}$ apresentou resposta linear crescente $(\mathrm{P}<0,01)$ ao aumento do teor de PB. Sahlu et al. (1993b), que não constataram diferença em relação ao consumo de MS, também observaram que a ingestão de PB refletiu a porcentagem de PB dietética. 
Tabela 2 - Médias, coeficientes de variação (CV) e determinação $\left(r^{2}\right)$ e equações de regressão ajustadas para os consumos de MS, MO, PB, PDR, EE, CT, FDN, CNF e NDT, de acordo com os níveis de PB nas dietas

Table 2 - Means, coefficients of variation (CV) and determination $\left(r^{2}\right)$ and adjusted regression equations for the intakes of DM, OM, CP, RDP, EE, TC, NDF, NFC and TDN for goats fed increasing dietary CP levels

\begin{tabular}{ccccccc}
\hline \multicolumn{9}{c}{ Nível de PB (\%) } \\
CP level
\end{tabular}

\begin{tabular}{|c|c|c|c|c|c|c|c|}
\hline \multirow[b]{2}{*}{$\operatorname{MS}(D M)^{1}$} & \multicolumn{3}{|c|}{$\begin{array}{l}\text { Consumo } \\
\text { Intake }\end{array}$} & \multirow[b]{2}{*}{2,28} & \multirow[b]{2}{*}{11,5} & \multirow[b]{2}{*}{0,94} & \multirow[b]{2}{*}{$\hat{\mathrm{Y}}=1,385+0,05 * * \mathrm{~PB}$} \\
\hline & 1,99 & 2,02 & 2,16 & & & & \\
\hline MO $(O M)^{1}$ & 1,91 & 1,93 & 2,06 & 2,17 & 11,4 & 0,94 & $\hat{\mathrm{Y}}=1,36+0,045 * * \mathrm{~PB}$ \\
\hline $\mathrm{PB}(C P)^{2}$ & 241 & 290 & 368 & 448 & 9,6 & 0,99 & $\hat{\mathrm{Y}}=-133,86+32,245^{* *} \mathrm{~PB}$ \\
\hline $\operatorname{PDR}(R D P)^{2}$ & 162 & 195 & 248 & 302 & 9,6 & 0,99 & $\hat{\mathrm{Y}}=-92,332+21,872 * * \mathrm{~PB}$ \\
\hline $\mathrm{EE}^{2}$ & 58 & 46 & 47 & 51 & 17,2 & 0,93 & $\hat{\mathrm{Y}}=278,3-31,1 \mathrm{~PB}+1,04 * * \mathrm{~PB}^{2}$ \\
\hline $\mathrm{CNF}(N F C)^{1}$ & 1,05 & 1,04 & 1,07 & 1,06 & 11,0 & - & $\hat{\mathrm{Y}}=1,0565$ \\
\hline \multirow[t]{2}{*}{ NDT $(T D N)^{1}$} & 1,56 & 1,57 & 1,71 & 1,82 & 12,0 & 0,93 & $\hat{\mathrm{Y}}=1,015+0,0447 * \mathrm{~PB}$ \\
\hline & \multicolumn{4}{|c|}{$\begin{array}{c}\text { Consumo (\% PV) } \\
\text { Intake }(\% \quad B W)\end{array}$} & & & \\
\hline $\mathrm{MS}(D M)$ & 3,93 & 4,05 & 4,30 & 4,54 & 11,8 & 0,98 & $\hat{\mathrm{Y}}=2,76+0,0988^{* *} \mathrm{~PB}$ \\
\hline
\end{tabular}

** $\mathrm{e}^{* * *}$ significativo a 1 e $10 \%$ de probabilidade, respectivamente, pelo teste $\mathrm{t}$.

1 (kg/dia), 2 (g/dia)

${ }^{* *}$ and ${ }^{* * *}$ significant at 1 and $10 \%$, respectively, by test.

Utilizando-se as equações propostas pelo NRC (1981), AFRC (1993) e as Tabelas de Composição de Alimentos (Valadares Filho et al., 2002), foram estimados os consumos de proteína metabolizável (PMet), proteína degradada no rúmen (PDR) e NDT. Os valores observados e preditos por meio de equações são apresentados na Tabela 3. Os consumos de MS observados encontram-se próximos àqueles preditos pelo AFRC (1993).

Quanto aos níveis de $\mathrm{PB}$, apenas na dieta contendo $11,5 \%$ de $\mathrm{PB}$, as cabras consumiram quantidade de $\mathrm{PB}$ próxima à recomendada pelo NRC (1981). Nas demais, os consumos de $\mathrm{PB}$ foram superiores às exigências (Tabela 3 ) $\mathrm{e}$, portanto, houve excesso em relação às exigências propostas pelo NRC (1981) e pelo AFRC (1993).

Embora o consumo de $\mathrm{PB}$ pelos animais submetidos à dieta com $11,5 \%$ de $P B$ tenha sido próximo às exigências deste nutriente, nesta dieta, a exigência de PMet não foi atendida. Quando as cabras consumiram a dieta com 13,5\% de PB, a exigência de PMet estimada pelo AFRC (1993) foi suprida. As dietas com 15,5 e 17,5\% excederam as exigências de PMet e PDR propostas pelo AFRC (1993).

A produção de leite (PL) e os conteúdos de gordura e PB do leite estão apresentados na Tabela 4. A PL relacionou-se linear e positivamente $(\mathrm{P}<0,1)$ aos níveis de $\mathrm{PB}$ na dieta, como conseqüência do aumento do consumo e da digestibilidade da MS e dos nutrientes citados.
Lu et al. (1987) forneceram níveis de 12, 15 e $18 \%$ de PB na dieta de cabras lactantes e constataram diferença significativa na produção de leite entre os grupos alimentados com as dietas com 12 e $18 \%$ de PB (1,7 e 2,4 kg de leite/dia, respectivamente). Badamana et al. (1990) e Badamana \& Sutton (1992) observaram aumento linear da produção leiteira de cabras com o aumento do nível de proteína do concentrado. Sahlu et al. (1993b), no entanto, não observaram efeito significativo do teor de PB da dieta sobre a produção de leite de cabras.

A produção de leite corrigida (PLC) para 3,5\% de gordura foi similar $(\mathrm{P}>0,1)$ entre as cabras submetidas a diferentes níveis de $\mathrm{PB}$ na dieta, o que pode ser conseqüência da ausência de efeito de tratamento sobre os teores e a produção diária de gordura do leite.

Embora a produção de leite tenha aumentado $(\mathrm{P}<01)$, à medida que foram elevados os níveis de $\mathrm{PB}$ na ração, houve declínio $(\mathrm{P}<0,01)$ na eficiência de utilização de nitrogênio. O consumo de PB na dieta com $11,5 \%$ deste nutriente foi semelhante ao recomendado pelo NRC (1981), mas excedeu as recomendações do NRC (1981) e do AFRC (1993) nos níveis mais elevados de inclusão na dieta.

Segundo as recomendações do NRC (1981), o consumo de 256,2 g de PB seria suficiente para atender à exigência para produção de $3,08 \mathrm{~kg}$. O consumo de PB aumentou 206,6 g (Tabela 2) entre as dietas com 11,5 e 17,5\% PB para 
Tabela 3 - Valores médios observados e preditos para o consumo de MS, consumo e exigência de PB, PMet e NDT obtidos com as dietas contendo diferentes níveis de PB

Table 3 - Observed and predicted averaged values for dry matter (DM) intake, intake and requirement of $C P$, metabolizable protein (PMet) and TDN for goats fed increasing dietary CP levels

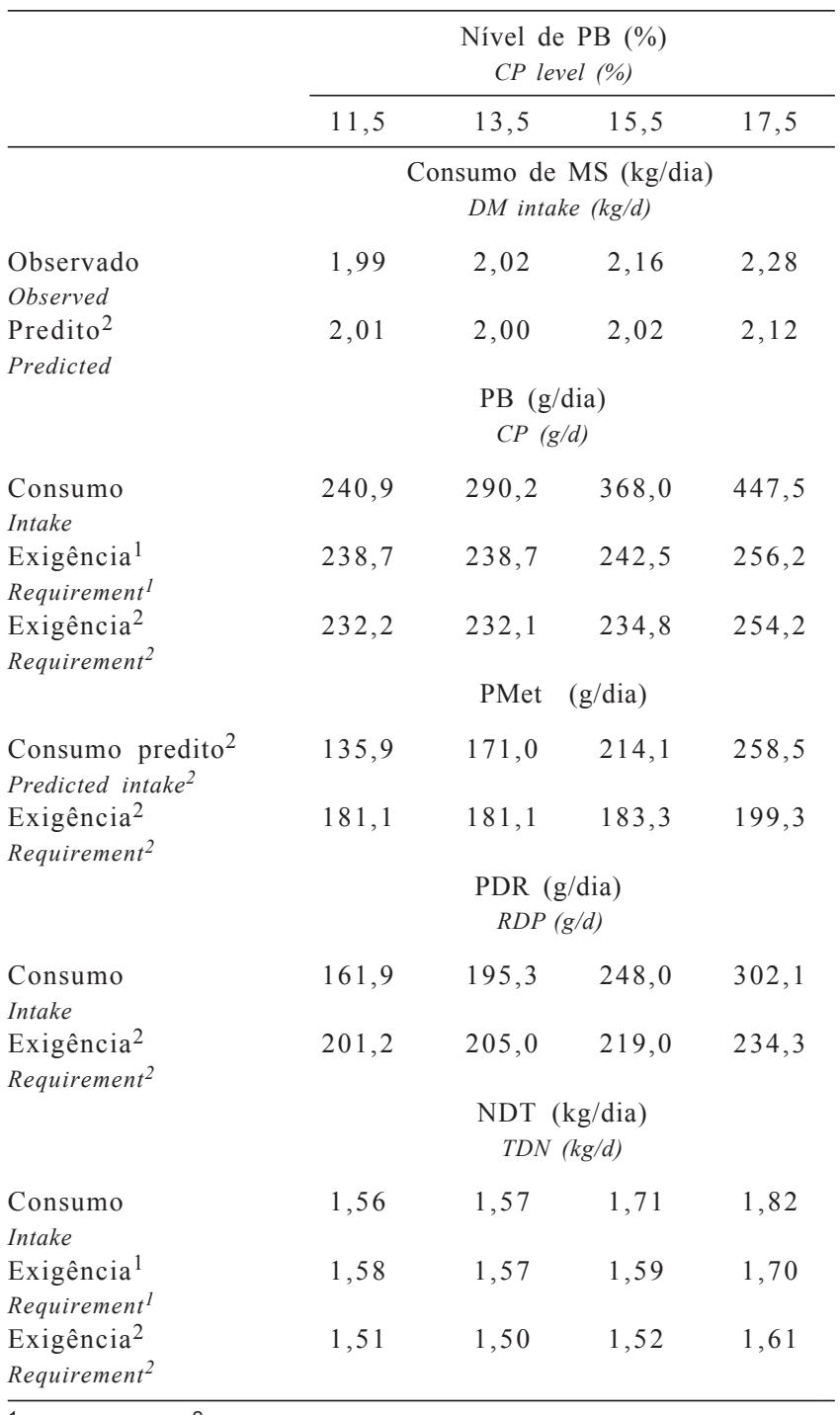

${ }^{1} \mathrm{NRC}(1981), \quad{ }^{2} \mathrm{AFRC}(1993) \rightarrow \mathrm{PB}$.

que houvesse aumento de $364 \mathrm{~g}$ na produção de leite. $\mathrm{O}$ excesso no consumo de $\mathrm{PB}$ pode estar relacionado à diminuição da eficiência de utilização do $\mathrm{N}$ dietético.

Entre os constituintes avaliados no leite, apenas a produção de PB (em gramas) foi afetada pelo teor de PB da dieta, apresentando comportamento linear crescente com o aumento do nível de PB dietético.

$\mathrm{Na}$ Tabela 5 são apresentados os coeficientes de digestibilidade médios de MS, MO, PB, EE, CT, FDN e CNF, os respectivos coeficientes de variação e determinação e as equações de regressão, de acordo com o teor de PB das dietas. O coeficiente de digestibilidade de MS apresentou médias de 77,$4 ; 78,3 ; 80,0$ e $80,4 \%$, respectivamente, para as dietas com 11,$5 ; 13,5 ; 15,5$ e 17,5\% de PB. Estas médias são semelhantes às observadas por Batista et al. (1994), Brun-Bellut et al. (1991) e Cerrillo et al. (1999). Os valores observados neste trabalho são próximos aos relatados por Bonfim (2003), que encontrou em cabras lactantes valores de digestibilidade aparente da MS de 71,2 a 77,1\%.

A digestibilidade aparente da MS foi influenciada de forma linear $(\mathrm{P}<0,01)$ pelos níveis de PB das dietas. Sahlu et al. (1993a) também verificaram melhor digestibilidade aparente da MS por cabras alimentadas com níveis mais elevados de PB na dieta. Badamana \& Sutton (1992), no entanto, não verificaram diferenças nas digestibilidades da MS e da MO. Singh \& Mudgal (1987), Badamana et al. (1990) e SotoNavarro et al. (2003) observaram incremento nas digestibilidades da $\mathrm{MO}$ e $\mathrm{PB}$ com o aumento no teor de $\mathrm{PB}$ na dieta de cabras lactantes.

Da mesma forma que a digestibilidade da MS, o coeficiente de digestibilidade da $\mathrm{MO}$ apresentou comportamento linear crescente $(\mathrm{P}<0,01)$ com a elevação do conteúdo de $\mathrm{PB}$ da dieta.

Os coeficientes de digestibilidade aparente dos CT e CNF também apresentaram resposta linear crescente ao incremento de PB da dieta. Singh \& Mudgal (1987) notaram elevação na digestibilidade dos CT com o aumento de PB da dieta de cabras. Os resultados dos coeficientes de digestibilidade aparente dos CNF observados nas dietas com 13,$5 ; 15,5$ e $17,5 \%$ de PB foram superiores a $90 \%$, enquanto, no tratamento com $11,5 \%$ de $\mathrm{PB}$, foi de $89,3 \%$. A resposta crescente em relação aos $\mathrm{CT}(\mathrm{P}<0,05)$ para os níveis de $\mathrm{PB}$ nas dietas possivelmente foi influenciada pela melhora na digestibilidade dos CNF. A digestibilidade aparente da FDN, por sua vez, não foi alterada $(\mathrm{P}>0,05)$ pelo aumento de PB nas dietas.

$O$ coeficiente de digestibilidade aparente da $\mathrm{PB}$ também aumentou significativamente $(\mathrm{P}<0,01)$ com o teor de PB nas dietas, em razão da maior ingestão de compostos nitrogenados e, conseqüentemente, da progressiva diminuição da contribuição do $\mathrm{N}$ endógeno nos compostos nitrogenados fecais (Robinson \& Forbes, 1970; Ezequiel, 1987; e Cameron, 1991, citados por Valadares et al., 1997).

A digestibilidade do $\mathrm{EE}$ apresentou resposta quadrática $\left(\mathrm{R}^{2}=0,99\right.$ e $\left.\mathrm{P}=0,0256\right)$ conforme a equação: $\hat{\mathrm{Y}}=201,28-15,5 \mathrm{~PB}+0,5 \mathrm{~PB}^{2}$. A digestibilidade mínima foi estimada em $81,15 \%$ na dieta com $15,5 \%$ de PB. 
Tabela 4 - Médias, coeficientes de variação (CV\%) e equações de regressão ajustadas para produção de leite (PL), produção de leite corrigida (PLC) para 3,5\% de gordura, eficiência alimentar (Efic MS), eficiência de utilização de N (Efic N) e teores de gordura (G) e PB do leite (PBL), de acordo com o nível de PB nas dietas

Table 4 - Means, coefficients of variation (CV) and determination $\left(r^{2}\right)$ and adjusted regression equations for milk yied (MY), milk yield corrected for $3.5 \%$ of fat (FCM), feed efficiency, nitrogen efficiency (Efic N) and contents and yield of milk fat and milk protein for goats fed increasing dietary CP levels

\begin{tabular}{|c|c|c|c|c|c|c|c|}
\hline \multirow[b]{2}{*}{ Item } & \multicolumn{4}{|c|}{$\begin{array}{c}\text { Nível de PB (\%) } \\
\text { CP level }\end{array}$} & \multirow[b]{2}{*}{$\mathrm{CV} \%$} & \multirow[b]{2}{*}{$\mathrm{r}^{2}$} & \multirow[b]{2}{*}{$\begin{array}{l}\text { Equação ajustada } \\
\text { Adjusted equation }\end{array}$} \\
\hline & 11,5 & 13,5 & 15,5 & 17,5 & & & \\
\hline $\mathrm{PL}, \mathrm{kg} / \mathrm{dia}(M Y, \mathrm{~kg} / \mathrm{d})$ & 2,717 & 2,723 & 2,761 & 3,081 & 15,8 & 0,70 & $\hat{\mathrm{Y}}=2,001+0,0565^{* * *} \mathrm{~PB}$ \\
\hline PLC, kg/dia $(F C M, k g / d)$ & 2,440 & 2,407 & 2,462 & 2,664 & 16,3 & - & $\hat{Y}=2,494$ \\
\hline Efic MS (Feed efficiency) & 1,37 & 1,34 & 1,27 & 1,35 & 9,9 & - & $\hat{\mathrm{Y}}=1,335$ \\
\hline $\mathrm{G}, \mathrm{g} / \mathrm{d}$ (Milk fat, $\mathrm{g} / \mathrm{d}$ ) & 78,2 & 76,0 & 78,4 & 82,4 & 17,9 & - & $\hat{\mathrm{Y}}=78,7$ \\
\hline PBL, \% (Milk CP, \%) & 2,85 & 2,98 & 2,97 & 2,95 & 6,3 & - & $\hat{\mathrm{Y}}=2,94$ \\
\hline PBL, g/d (Milk $C P, g / d)$ & 77,6 & 80,0 & 80,1 & 91,3 & 16,5 & 0,75 & $\hat{\mathrm{Y}}=52,5965+2,046 * \mathrm{~PB}$ \\
\hline
\end{tabular}

** ${ }^{*} \mathrm{e}^{* * *}$ significativo a 1,5 e $10 \%$ de probabilidade, respectivamente, pelo teste $\mathrm{t}$.

**, * and ${ }^{* * *}$ significant at 1,5 and $10 \%$, respectively, by t test.

Tabela 5 - Médias, coeficientes de variação $(C V)$ e determinação $\left(r^{2}\right)$ e equações de regressão ajustadas para os coeficientes de digestibilidade aparente de MS, MO, PB, EE, CT, FDN e CNF, de acordo com os níveis de PB nas dietas

Table 5 - Means, coefficients of variation (CV) and determination $\left(r^{2}\right)$ and adjusted regression equations for the coefficients of apparent digestibility of DM, $O M, C P, E E, T C, N D F$, and NFC for goats fed increasing dietary CP levels

\begin{tabular}{|c|c|c|c|c|c|c|c|}
\hline \multirow[b]{2}{*}{ Item } & \multicolumn{4}{|c|}{$\begin{array}{c}\text { Nível de PB (\%) } \\
\text { CP level }\end{array}$} & \multirow[b]{2}{*}{$\mathrm{CV} \%$} & \multirow[b]{2}{*}{$\mathrm{r}^{2}$} & \multirow[b]{2}{*}{$\begin{array}{l}\text { Equação ajustada } \\
\text { Adjusted equation }\end{array}$} \\
\hline & 11,5 & 13,5 & 15,5 & 17,5 & & & \\
\hline $\mathrm{MS}(D M)$ & 77,4 & 78,3 & 80,0 & 80,4 & 3,4 & 0,95 & $\hat{\mathrm{Y}}=72,13+0,472 * * \mathrm{~PB}$ \\
\hline MO (OM) & 78,4 & 79,4 & 81,0 & 81,5 & 3,4 & 0,96 & $\hat{\mathrm{Y}}=73,07+0,48^{*} * \mathrm{~PB}$ \\
\hline $\mathrm{PB}(C P)$ & 75,9 & 78,7 & 81,8 & 83,6 & 5,2 & 0,99 & $\hat{\mathrm{Y}}=62,86+1,176 * \mathrm{~PB}$ \\
\hline EE & 90,3 & 84,8 & 83,3 & 86,0 & 5,6 & 0,99 & $\hat{\mathrm{Y}}=201,3-15,5 \mathrm{~PB}+0,5^{*} * \mathrm{~PB}^{2}$ \\
\hline $\mathrm{CT}(T C)$ & 78,3 & 79,2 & 80,7 & 80,7 & 3,5 & 0,98 & $\hat{\mathrm{Y}}=74,0+0,39 \mathrm{~PB} * \mathrm{~PB}$ \\
\hline $\mathrm{FDN}(N D F)$ & 56,2 & 57,1 & 59,4 & 60,0 & 11,1 & - & $\hat{\mathrm{Y}}=58,168$ \\
\hline $\mathrm{CNF}(N F C)$ & 89,3 & 90,2 & 91,8 & 92,3 & 2,3 & 0,97 & $\hat{\mathrm{Y}}=83,9+0,476^{* * \mathrm{~PB}}$ \\
\hline
\end{tabular}

* $e^{* *}$ significativo a 5 e $1 \%$ de probabilidade, respectivamente, pelo teste $t$.

* and ** significant at 5 and $1 \%$, respectively, byt test.

\section{Conclusões}

O aumento do teor de PB da dieta melhorou o consumo e a digestibilidade aparente da maioria dos nutrientes.

Os teores de $13,5 \%$ de PB na dieta ou $290 \mathrm{~g}$ de $\mathrm{PB} /$ dia foram suficientes para atender às exigências de cabras Alpinas em lactação e, portanto, podem ser recomendados para cabras com produção diária de leite corrigido para 3,5\% de gordura de até $2,7 \mathrm{~kg}$.

\section{Literatura Citada}

AGRICULTURAL AND FOOD REASERCH COUNCIL - AFRC. Energy and protein requirements of ruminants. Wallingford: CAB International, 1993. 159p.

BADAMANA, M.S.; SUTTON J.D.; OLDHAM, J.D. et al. The effect of amount of protein in the concentrates on hay intake and rate of passage, diet digestibility and milk production in British Saanen goats. Animal Production, v.51, p.333-342, 1990.

BADAMANA, M.S.; SUTTON, J.D. Hay intake, milk production, and rumen fermentation in British Saanen goats given concentrates varying widely in protein concentration. Animal Production, v.54, p.395-403, 1992.

BATISTA, A.M.V.; COELHO DA SILVA, J.F.; VALADARES FILHO, S.C. et al. Consumo, taxa de passagem e digestão em cabras não-gestantes e não-lactantes e no terço final da gestação. Revista Brasileira de Zootecnia, v.23, n.1, p.149-155, 1994.

BOMFIM, M.A.D. Carboidratos solúveis em detergente neutro em dietas de cabras leiteiras. Viçosa, MG: Universidade Federal de Viçosa, 2003. 240p. Tese (Doutorado em Zootecnia) - Universidade Federal de Viçosa, 2003.

BRUN-BELLUT, J.; KELLY, J. M.; MATHISON, G.W et al. Effect of rumen degradable protein and lactation on nitrogen metabolism in dairy goats. Canadian Journal of Animal Science, v.71, p.1111-1124, 1991.

CARVAlHO, S.; RODRIGUES, M.T.; BRANCO, R.H. et al. Comportamento ingestivo de cabras Alpinas em lactação alimentadas com dietas contendo diferentes níveis de fibra em 
detergente neutro proveniente da forragem. Revista Brasileira de Zootecnia, v.35, n.2, p.562-568, 2006.

CERRILLO, M.A.; RUSSEL, J.R.; CRUMP, M.H. The effects of hay maturity and forage to concentrate ratio on digestion kinetics in goats. Small Ruminant Research, v.32, p.51-60, 1999.

DEVENDRA, C. Goat: dietary factors affecting milk secretion and composition. International Goat and Sheep Research, v.2, p.61-76, 1982.

GAINES, W.L. The energy basis of measuring milk yield in dairy cows. Illinois: Illinois Agricultural Experiment Station Bulletin 308, 1928 (paginação descontínua).

LU, C.D.; POTCHOIBA, M.J.; COLEMAN L. Effect of dietary energy density and protein level on lactation in dairy goats. In INTERNATIONAL CONFERENCE ON GOATS, 4., 1987, Brasília. Proceedings... Brasília: EMBRAPA, 1987. p.1390.

MORAND-FEHR, P.; SAUVANT, D. Composition and yield of goat milk as affected by nutritional manipulation. Journal of Dairy Science, v.63, p.1671-1680, 1980.

NATIONAL RESEARCH COUNCIL - NRC. Subcommittee on Goat Nutrition. Nutrient requirements of goats. Washington, D.C.: National Academy of Sciences, 1981. 91p.

RODRIGUES, M.T. Uso de fibras em rações de ruminantes. In: CONGRESSO NACIONAL DOS ESTUDANTES DE ZOOTECNIA, 1998, Viçosa, MG. Anais... Viçosa, MG: Universidade Federal de Viçosa, 1998. p.139-171.

SAHLU, T.; FERNANDEZ, J.M.; LU, C.D. et al. Dietary protein level and ruminal degradability for mohair production in Angora goats. Journal of Animal Science, v.70, p.1523-1533. 1992.

SAHLU, T.; HART, S.P.; FERNANDEZ, J.M. Nitrogen metabolism and blood metabolites in three goat breeds fed increasing amounts of protein. Small Ruminant Research, v.10, p.281-292, 1993a.

SAHLU, T.; FERNANDEZ J.M.; JIA Z.H. et al. Effect of source and amount of protein on milk production in dairy goats. Journal of Dairy Science, v.76, p.2701-2710, 1993b.

SANTINI, F.J.; LU, C.D.; POTCHOIBA, M.J. et al. Dietary fiber and milk yield, mastigation, digestion and passage in goats fed alfalfa hay. Journal of Dairy Science, v.75, p.209-219, 1992.

SINGH, N.; MUDGAL, V.D. Utilization of various levels of dietary nitrogen by dairy goats. In: INTERNATIONAL CONFERENCE ON GOATS, 4., 1987, Brasília. Proceedings... Brasília: EMBRAPA, 1987. p.1415.
SILVA, J.D.; QUEIROZ, A.C. Análise de alimentos (métodos químicos e biológicos). 2.ed. Viçosa, MG: Universidade Federal de Viçosa, 2002. 156p.

SNIFFEN C.J.; O'CONNOR, J.D.; Van SOEST, P.J. et al. A net carbohydrate and protein system for evaluating cattle diets: II Carbohydrate and protein availability. Journal of Animal Science, v.70, p.3562-3577, 1992.

SOTO-NAVARRO, S.A.; GOETTSCH A.L.; SAHLU, T. et al. Effects of ruminally degraded nitrogen source and level in a high concentrate diet on site of digestion in yearling Boer $\mathrm{x}$ Spanish wether goats Small Ruminant Research, v.50, p.117-128, 2003.

UNIVERSIDADE FEDERAL DE VIÇOSA - UFV. SAEG - Sistema de análises estatísticas. Versão 8,0. Viçosa, MG: 1999. 141p. (Manual do usuário).

VALADARES, R.F.D.; GONÇALVES, L.C.; SAMPAIO, I.B. et al. Níveis de proteína em dietas de bovinos 2. Consumo, digestibilidades e balanço de compostos nitrogenados. Revista Brasileira de Zootecnia, v.26, n.6, p.1259-1263, 1997.

VALADARES FILHO, S.C.; ROCHA JR., V.R.; CAPPELLE, E.R. Tabelas brasileiras de composição de alimentos para bovinos. Viçosa, MG: Universidade Federal de Viçosa, 2002. 297p.

WEISS, W.P. Energy prediction equations for ruminant feeds. In: CORNELL NUTRITION CONFERENCE FOR FEED MANUFACTURERS, 61., 1999, Ithaca. Proceedings... Ithaca: Cornell University, 1999. p.176-185.

WILKINSON, J.M.; STARK, B.A. Producción comercial de cabras. Zaragoza: Acribia, 1987. 165p. 